\title{
Risk and Vulnerable, Medicalized Bodies
}

\section{ARST Pre-Conference at NCA, 2014}

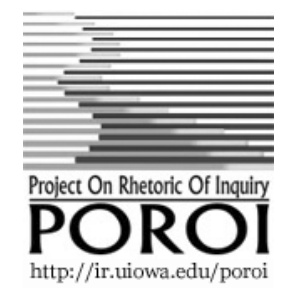

Amy Koerber

Texas Tech University

Lubbock, $T X$

\section{Lora Arduser}

University of Cincinnati

Cincinnati, $\mathrm{OH}$

Jeannie Bennett

Texas Tech University

Lubbock, $T X$

\section{Lauren Kolodziejski}

California Polytechnic State University - San Luis Obispo

San Luis Obispo, CA

\section{Shaunak Sastry}

University of Cincinnati

Cincinnati, $\mathrm{OH}$

\section{Paul Strait}

University of Southern California

Los Angeles, CA

Poroi 11,1 (May 2015)

In Ulrich Beck's risk society, modernization has generated a collection of humanly generated risks. These risks are largely the result of scientific and industrial development. They are not limited in time or space and they cross both generations and geographic boundaries. We often perceive ourselves as having little ability to calculate, and therefore, compensate for such risks (Lash and Wynne, 1992). This panel addressed how some of the most vulnerable bodies-children, pregnant women, fetuses, people diagnosed with mental illness-are sometimes articulated as targets for risk intervention and sometimes as inherently risky.

In her presentation, Lauren Kolodziejski discussed how visual elements articulate risk in the childhood vaccine controversy. 
Through an examination of common images incorporated in commentary around vaccine hesitancy, Kolodziejski noted how visual cues embedded within these images encourage viewing vaccines as risky among parents already feeling uncertain. A photograph of a child receiving a shot frequently accompanies articles about the vaccine issue, serving as a visual illustration of the issue to be discussed in the text that follows. A typical articulation of this image pictures the moment of injection, displaying a close-up shot of the needle being inserted into an arm, often cropped so closely that no faces are shown. For Kolodziejski, worth noting is how frequently in these images a faceless doctor or nurse administers the vaccine to the child, who looks on with apprehension or cries in pain. While such depictions emphasize the medical nature of inoculation, they also decontextualize the practice, abstracting it completely from a personalized practitionerpatient interaction.

Rhetorically, such images can undermine rather than encourage vaccine uptake. Studies have shown a correlation between lack of trust in the medical system or personal health care provider and lower vaccine coverage (Senier, 2008; Smith et al., 2011, 140). For parents who feel like vaccine policies are applied as one-size-fits-all, these images can reinforce impressions that health care workers are detached from or do not care about the individual receiving the vaccine. Since parents trying to make vaccine decisions may be exposed to media coverage more than to their own doctors particularly if they are prone to turning to the Internet for information - these images can subtly influence an uncertain parent's attitude.

Kolodziejski brought the widely disseminated image of vaccination to bear on the practice of displaying images of autistic children as "proof" for claims that vaccines cause autism. For example, at a "Green Our Vaccines" rally held in Washington, D.C. in 2008, parents marched holding up images of their own children. Rhetorically, these images operate as synecdoches for these parents' narratives and contrast with official depersonalized ones. They personalize the issue and visualize the claimed risk in a highly relatable way. The amassing of images serves as amplification, making the issue seem more widespread, thereby potentially creating a false consensus effect (Kahan, Slovic, Braman, and Gastil, 2010, 205), whereby parents might overestimate the numbers of other parents who are hesitant about or completely adverse to vaccines.

Kolodziejski concludes that visuals can enter conversations about risk in any number of ways, from supplements within media 
coverage to means for displaying technical information in a more understandable way. Rhetoricians have much to contribute in examining how these visuals articulate risks and how visuals might tap into the emotional component of risk perception and assessment.

Jeannie Bennett and Amy Koerber addressed the topic of "Articulating Risk" through a study of shifting risk perceptions in medical recommendations for treating bipolar disorder during pregnancy. Throughout most of its history, bipolar disorder has been seen as a condition that should not necessarily be treated with pharmaceuticals during pregnancy. In the last ten years, however, medical beliefs have dramatically shifted. Pregnancy, once thought to confer a protective effect against bipolar disorder (Grof et al. 2000), is now seen as a period of high risk for it (Viguera et al. 2002; Viguera et al. 2007). Whereas medication was once deemed too risky, the risks that an unmedicated woman poses to herself, her fetus, and those around her now seem to demand pharmaceutical intervention.

Bennett and Koerber begin by noting that the inherent riskiness of the bipolar pregnant woman, as depicted in today's medical literature, is grounded in fears of the hormonal fluctuation that is known to occur during pregnancy. In the current medical literature, women are reduced to their menstrual cycles, which are quantified to such a fine degree that women are, essentially, always in their menstrual cycles (see Burt and Ragson, 2004). For example, women with bipolar disorder are conceptualized as constantly in flux and moody; they are "doubly moody." Researchers and clinicians assume that a woman's hormones must in some way exacerbate bipolar disorder, making a woman more moody, more pathological and more uncontrollable than men with bipolar disorder (see Leibenluft, 1996, for example). Her body-mood is constructed as inherently pathological and dangerous for the fetus-more so than pharmaceutical intervention, which the physician can presumably monitor and control to a greater extent than is the case for a woman's own hormones.

The assumption that a woman's hormones must have some effect on bipolar disorder has, however, never been tested, but instead is taken as a given. Many researchers and clinicians frame their investigations of women and bipolar disorder with the assumption that hormones must, in some way, affect bipolar disorder, although the research has not yet demonstrated this link. Because researchers' efforts to find such a link are continually frustrated, Bennett and Koerber argued, the unproven assumption 
that a woman's hormones are a "special case" in bipolar disorder has become linked to an appeal for newer, better science.

Bennett and Koerber's claims about the rhetorical function of hormones in today's medical discourse on bipolar pregnant women were strengthened with reference to a brief history of "hormone" as a scientific term. The term was first used in a 1905 lecture by British physician Ernest Henry Starling. This lecture inserted itself into a contentious debate about what controls the human body: Is it only the brain and nervous system, or is something else involved? In reading Starling's account of this debate, we see traces of some common binaries in Western thought, including oppositions between logic and emotion and mind and body. We also see evidence that medical scientists were afraid of these newly discovered "chemical messengers," and that their fears were based in their desire to control the human body. As Starling says, "Absolute control over the workings of the human body is the goal of medical science."

This rhetorical history provides a useful frame for understanding some aspects of current medical discourse on the bipolar pregnant woman. The shift in medical recommendations is linked to medical beliefs about women's hormones, which are constructed as inherently risky, in a manner that reflects the same fears about control, and loss of control, that were expressed in Starling's 1905 lectures. As they continue this research, Bennett and Koerber hope to learn more about the reasons why these old fears have resurfaced in today's medical discourse.

Shaunak Sastry and Lora Arduser examined how current medical discourse on gestational diabetes mellitus, like much of the current medical discourse on pregnancy more generally, attempts to minimize risks. Most women in the United States come to know the risks of gestational diabetes through the discourses and practices of the modern prenatal system, a system that assumed its current form after World War II (Seigel, 2014). From that time forward, there was a national trend to centralize prenatal care in clinic or hospitals. This system is based on the assumption that the work of pregnancy is a healthy baby and that pregnant bodies are "sites through which social, political and environmental risks are managed" (Seigel, 2014, 13). Like the larger risk society Beck discusses, risks in this system do not necessarily increase, but risk does organize the system (Beck, 1992.)

Sastry and Arduser investigate how gestational diabetes is constructed as a risk, but also how women, as embodied agents, accept, negotiate, and challenge these risks. Their research derives 
from critical approaches to health communication in exploring how patients organize meanings around gestational diabetes and the power dynamics that inhere in the construction of such meanings (Dutta, 2010; Lupton, 1994, 2013; Zoller and Dutta, 2008). They analyzed the rhetorical construction of gestational diabetes risk within publicly available textual material and the construction of gestational diabetes risks by pregnant women. In an age where health and risk information is increasingly present online, pregnant women have access to significant amounts of information that communicate the risks, diagnoses, and management of gestational diabetes. Although in most cases, gestational diabetes is circumscribed to the duration of pregnancy, it is also associated with significant risks to both mother and child after pregnancy. Given these risks, and the significant comorbidities between gestational and Type 2 diabetes (itself a public health concern), an increasing number of women are exposed to messages and risk discourses around gestational diabetes. As of this writing, however, there has not yet been a systematic study of gestational diabetes from a health communication perspective.

Through their analysis Sastry and Arduser argue that the production of gestational diabetes risk discourse has theoretical and practical implications not merely as a mode of Foucaultian biopolitics, but also as a site of patient (and female) agency (Rose, 2007). At the preconference, they reported on the beginnings of their data collection, which included the discourse analysis of interview data $(\mathrm{n}=5)$ and a generative rhetorical criticism of biomedical texts on GDM (Kline, 2007). They discussed four themes that have emerged in their research: 1) desire for the "perfect birth," 2) surveillance 3) the notion of being a "responsible" mother, and 4) maternal vs. fetal risks.

In his contribution to the panel, L. Paul Strait examined the debate surrounding the proposal to include the diagnosis of psychosis risk syndrome (PRS) in the American Psychiatric Association's most recent diagnostic manual, DSM-5. Defining a state of affairs as a disease or illness (that is, its 'medicalization') has become an important rhetorical topic in contemporary medical discourse. Once formulated as a health concern and pathologized, a problem falls under the technical gaze of expertise as a putative disease entity, whenever acceptable subjective and objective criteria can be developed and institutionalized. Medicalization comes in two forms: "the pathologizing of normal biological or social variation and ... the portrayal of the presence of risk factors for disease as a disease state itself" (Heath, 2006, e146). The latter 
category, the medicalization of risk, has produced a new form of life-the asymptomatically or pre-symptomatically ill.

Although the proposed diagnostic category has been very controversial, psychiatry has long flirted with developing early interventions for those adolescents and young adults who are at risk for schizophrenia and other psychotic disorders, and over 100 clinics have been set up over the last decade to study PRS and its 'treatment' ( manovi, 2011). As a syndrome, PRS is characterized by a constellation of signs and symptoms whose clustering together suggests a medically relevant morbid unity, an underlying disease process that can be called by name, assigned a prognosis, and, in an ideal world, made to respond to a specific indicated treatment. In this case, however, the syndrome signifies in reality only a risk of developing a future disease process. In this case, however, the syndrome signifies only the risk of developing a future disease process, and the potential interventions-cognitive therapy, essential fatty acid supplementation, and the prophylactic administration of anti-psychotic medication-carry substantial risks of their own.

Because these risk factors are non-specific, approximately twothirds of those identified will not experience an acute psychotic episode within a two-year period absent any intervention (McGorry et al., 2009). Such a high false-positive rate magnifies the potential social, psychological, and biological hazards of intervention (Frances, 2010). Yet, in this controversy concepts like 'falsepositives' are contested in a polyphonic field of divergent perspectives concerning the etiology and pathogenesis of psychotic disorders. This field is characterized by an avoidance of an "interpretive-definitional" stasis point in the interests of consensusbuilding (Prelli, 1989, 146). Does the syndrome signify a risk state or the presence of attenuated psychotic symptoms? Does a diagnosis imply susceptibility, predisposition, prodrome, or probability? Is psychosis endopathogenic or exopathogenic? What does being 'at risk' entail beyond a prediction about one's future mental health? Unanswered (and unasked), these lingering questions distort evaluations of relative risk. Instead, interlocutors take up questions about the risks of legitimation: the unknown effects of pharmaceutical marketing to non-specialists. There also seems to be confusion about whether the points of dispute in the controversy are technical or practical in nature. These aspects of the controversy, Strait argues, reflect the rhetorical dynamics of risk society under conditions of reflexive modernity. The result is protracted dissensus, as of yet unresolved. 


\section{SUMMARY}

Although presenters explored four disparate topics, follow-up discussion and audience questions suggested some common threads that tied the presentations to each other and to the preconference theme of "Articulating Risk." One important theme is the manner in which articulations of risk can change so dramatically from one era to the next. In different ways, each of the risk-related topics addressed by the four presenters on the panel can be usefully illuminated through Judy Segal's notion of kairology; that is, an individual or condition that is perceived as risky at one time and place in history might have been perceived as entirely safe at another time and place. Another important theme was the question of agency. On this theme, some important differences emerged among the four presentations. For the topics addressed in the Bennett-Koerber and the Sastry-Arduser presentations, discussions of agency emerged from questions about the maternal-fetal dyad and actions that pregnant mothers are expected to take to protect the fetus. For the topic of Kolodziejski's presentation, discussions of agency assume the adult parent to be a decision maker about vaccines, even though the child is the one who is the object of the perceived risks that are in question. For the topic addressed by Strait, the DSM apparatus is a means by which experts can steer the broader institutional practices of psychiatry, but concerns over their agency as experts ultimately proved to be the dispositive risk in the controversy. Despite these differences, an important point of consensus among the panelists was the need to resist simple definitions of risky situations that too readily assign responsibility for managing risk to the most vulnerable individuals in our society, but at the same time to make sure we articulate risks in ways that protect those in society who are the most vulnerable. Achieving this delicate balance will require different kinds of decision-making and rhetorical agency in different kinds of risk articulations, as exemplified in the four diverse topics addressed in this presentation. 


\section{REFERENCE LIST}

Beck, U. Risk Society: Towards a New Modernity. New Delhi: Sage, 1992.

Burt, V.K. and N. Ragson, "Special Considerations in Treating Bipolar Disorder in Women." Bipolar Disorders 6 (2004): 213.

Dutta, M. J. "The Critical Cultural Turn in Health Communication: Reflexivity, Solidarity, and Praxis." Health Communication 25 (2010): 534-539.

Frances, A. J. "DSM5 'Psychosis Risk Syndrome'--Far Too Risky." Psychology Today (2010): http://www.psychologytoday.com/blog/dsm5-indistress/201003/dsm5-psychosis-risk-syndrome-far-too-risky, accessed 2/7/12.

Grof, P., W. Robbins, A. Matin, A. Berghoefer, M. Vojtechovsky, A. Nilsson, and C. Robertson. "Protective Effect of Pregnancy in Women with Lithium-Responsive Bipolar Disorder." Journal of Affective Disorders 61 (2000): 31-39.

Kline, K. N. "Cultural Sensitivity and Health Promotion: Assessing Breast Cancer Education Pamphlets Designed for African American Women." Health Communication 21 (2007): 85-96.

Heath, I. "Combating Disease Mongering: Daunting But Nonetheless Essential.” PLoS Med 3(2006): e146. doi:10.1371/journal.pmed.0030146

Kahan, D., P. Slovic, D. Braman, and J. Gastil. "Fear of Democracy: A Cultural Evaluation of Sunstein on Risk: A Review of Laws of Fear: Beyond the Precautionary Principle (2005) by Cass R. Sunstein.” In P. Slovic (Ed.) The Feeling of Risk: New Perspectives on Risk Perception. (Pp. 183-213). London: Earthscan, 2010.

Kecmanovi, D. Controversies and Dilemmas in Contemporary Psychiatry. New Brunswick, NJ: Transaction Publishers, 2011.

Leibenluft, E. "Women with Bipolar Illness: Clinical and Research Issues.” American Journal of Psychiatry 153 (1996): 163-173. 
Lupton, D. "Toward the Development of Critical Health Communication Praxis." Health Communication 6 (1994): 55-67.

Risk. London: Routledge, 2013.

McGorry, P. D., B. Nelson, G.P. Amminger, A. Bechdolf, S.M. Francey, G. Berger, et al. "Intervention in Individuals at Ultra-High Risk for Psychosis: A Review and Future Directions." Journal of Clinical Psychiatry 70(2009): 12061213.

Prelli, L. J. A Rhetoric of Science: Inventing Scientific Discourse. Columbia, SC: University of South Carolina Press, 1989.

Rose, N. The Politics of Life Itself: Biomedicine, Power, and Subjectivity in the Twenty-first Century. Princeton, NJ: Princeton University Press, 2007.

Seigel, M. The Rhetoric of Pregnancy. Chicago: the University of Chicago Press, 2014.

Senier, L. “It's Your Most Precious Thing:' Worst-case Thinking, Trust, and Parental Decision Making about Vaccinations." Sociological Inquiry 78 (2008): 207-229.

Smith, P. J., S.G. Humiston, E.K. Marcuse, Z. Zhao, C.G. Dorell, C. Howes, and B. Hibbs. "Parental Delay or Refusal of Vaccine Doses, Childhood Vaccination Coverage at 24 Months of Age, and the Health Belief Model." Public Health Reports 126 Suppl 2 (2011): 135-146.

Starling, E.H. "The Croonian Lectures." Lancet 26 (1905): 579-583.

Viguera, A.C., L.S. Cohen, R.J. Baldessarini, R. Nonacs. "Managing Bipolar Disorder During Pregnancy: Weighing the Risks and Benefits." Canadian Journal of Psychiatry 47 (2002): 426436.

Viguera, A.C., T. Whitfield, R.J. Baldessarini, D.J. Newport, Z. Stowe, A. Reminick, A. Zurick, L.S. Cohen. "Risk of Recurrence in Women with Bipolar Disorder during Pregnancy: Prospective Study of Mood Stabilizer Discontinuation.” American Journal of Psychiatry 164 (2007): 1817-1824.

Zoller, H. M., and M.J. Dutta. Emerging Perspectives in Health Communication: Meaning, Culture, and Power. New York: Routledge/Taylor and Francis Group, 2008. 